\title{
Produtividade e teor de sólidos solúveis de frutos de cultivares de mo- rangueiro em ambiente protegido
}

\author{
Juliano Tadeu V de Resende; Rafael Gustavo F Morales; Marcos V Faria; Adriano Luiz L Rissini; Letícia \\ KP Camargo; Cristhiano K Camargo \\ UNICENTRO-Depto. Agronomia, CEDETEG, C. Postal 3010, 85040-080 Guarapuava-PR; jresende@unicentro.br
}

\section{RESUMO}

O cultivo protegido é uma alternativa para controlar variações climáticas em diferentes locais e épocas de plantio, entretanto, seus efeitos e interações com a cultura do morangueiro ainda são pouco conhecidos. O objetivo desse trabalho foi avaliar a influência de três sistemas de cultivo (túnel alto, túnel baixo e a campo) na produtividade, massa média de frutos e no teor de sólidos solúveis dos frutos das cultivares de morango Dover, Camarosa, Sweet Charlie e Oso Grande em Guarapuava-PR. Quanto à produtividade e massa média de frutos, a cultivar Camarosa foi a melhor nos cultivos em túnel, tanto alto quanto baixo, pelo seu excelente desempenho. Os frutos da cultivar Sweet Charlie apresentaram o maior teor de sólidos solúveis nos três ambientes de cultivo. A produtividade e a massa média dos frutos foram significativamente superiores nos cultivos em túneis, alto e baixo, quando comparados ao cultivo a campo. O ambiente que propiciou maior acúmulo de sólidos solúveis nos frutos foi o túnel alto, diferindo significativamente dos demais ambientes de cultivo.

Palavras-chave: Fragaria $x$ ananassa, túnel alto, túnel baixo.

\begin{abstract}
Yield and soluble solids contents of fruits of strawberry cultivars in protected cultivation

Protected cultivation is an alternative to control the climatic effects in different places and times of planting, however, its effects and interactions with the strawberry crop are little known. The goal of this study was to evaluate the effects of three cropping systems (high tunnel, low tunnel and field) on yield, mean fruit mass and the soluble solids contents of strawberry cultivars Dover, Camarosa, Sweet Charlie and Oso Grande in Guarapuava. Camarosa cultivar presents an excellent performance regarding yield and mean fruit mass in high and low tunnel cultivation; hence, these cropping system can be indicated. Fruits of Sweet Charlie cultivar had the highest content of soluble solids in all the cultivation environments. Yield and mean fruit mass obtained from high and low tunnels were significantly higher than in the field. The environment high tunnel allowed greater accumulation of soluble solids, differing significantly from other evaluated environments.
\end{abstract}

Keywords: Fragaria x ananassa, high tunnel, low tunnel.

(Recebido para publicação em 27 de abril de 2009; aceito em 17 de maio de 2010) (Received on April 27, 2009; accepted on May 17, 2010)

A concentração da produção de morangos no período de safra é o principal fator responsável pelos baixos preços observados, gerando uma menor rentabilidade aos produtores. Os melhores preços são obtidos nos meses de março a junho, quando a oferta do produto é muito pequena no Brasil (Verdial, 2004). A antecipação ou atraso da colheita, visando comercializar o produto na época de maior retorno econômico, é uma estratégia para aumentar a rentabilidade dos produtores (Ronque, 1998; Carvalho et al., 2005).

O crescimento da demanda, aliado à necessidade de produzir o ano todo, vem despertando o interesse por novas técnicas de cultivo. Desta forma, o cultivo protegido se destaca como alternativa para solucionar tais problemas, proporcionando uma série de vantagens, tais como: proteção da cultura contra ventos, granizo, chuvas e geadas (Antunes et al., 2007), controle de temperatura e umidade (Goto \& Tivelli, 1998; Vásquez et al., 2005) e menor ocorrência de doenças fúngicas e bacterianas devido à redução do molhamento foliar (Pires et al., 1999).

As alterações do ambiente, provocadas pela utilização do cultivo protegido, estão relacionadas principalmente à temperatura do ar (Ronque, 1998). Scatolini (1996) relata maior efeito da cobertura plástica sobre as temperaturas máximas com valores de 1,2 a $4,4^{\circ} \mathrm{C}$ acima das observadas externamente. Com relação às temperaturas mínimas do ar, essas tendem a ser iguais ou ligeiramente superiores à observada externamente, sendo afetadas pelo tipo de ambiente protegido e manejo da ventilação durante o dia (Buriol et al., 1993).

A temperatura afeta o potencial de florescimento do morangueiro, fato observado por Bueno et al. (2002) devido ao seu efeito na velocidade das reações bioquímicas e dos processos internos de transporte de seiva. Segundo Jones (1992), o aumento da temperatura do ar impulsiona o processo de transpiração e também altera a temperatura dos tecidos vegetais com conseqüência para a taxa dos processos metabólicos e o balanço entre eles.

O manejo das variáveis ambientais, por meio do cultivo protegido, está atrelado não somente ao aumento da produção, mas também à qualidade dos frutos. Este último pode ser medido em parte pelo teor de sólidos solúveis que, segundo Goto \& Tivelli (1998), varia entre as cultivares e as condições ambientais. $\mathrm{O}$ teor de sólidos solúveis é característica de interesse, principalmente para frutos comercializados in natura, pois o mercado consumidor prefere frutos doces (Conti et al., 2002).

O objetivo desse trabalho foi avaliar 
a influência de diferentes ambientes de cultivo na produtividade, na massa média e no teor de sólidos solúveis de frutos de quatro cultivares de morangueiro, cultivadas no terceiro planalto paranaense, no município de Guarapuava-PR.

\section{MATERIAL E MÉTODOS}

O experimento foi realizado no período de julho de 2006 a janeiro de 2007, no Setor de Olericultura da Universidade Estadual do Centro-Oeste, em Guarapuava, Centro-Sul do Paraná (latitude: $25^{\circ} 23^{\prime} \mathrm{S}$, longitude: $51^{\circ} 27^{\prime} \mathrm{W}$, altitude média de $1.100 \mathrm{~m}$, clima $\mathrm{Cfb}$ ) em Latossolo Bruno Distroférrico típico de textura argilosa (Embrapa, 2006).

Os sistemas de cultivo adotados foram: túnel alto, túnel baixo e a campo. $\mathrm{O}$ delineamento experimental de cada um dos três sistemas foi de blocos casualizados, com 4 repetições. A parcela apresentou área útil de $2 \mathrm{~m}^{2}$ com 18 plantas em canteiros de $0,20 \mathrm{~m}$ de altura por 1,0 $\mathrm{m}$ de largura cobertos com mulching, adotando-se o espaçamento de $0,30 \mathrm{x}$ $0,30 \mathrm{~m}$, conforme recomendado por Groppo et al. (1997). Foram testadas quatro cultivares de morango, a saber: Dover que apresenta boa produtividade e fruto pequeno; Sweet Charlie que produz frutos grandes e adocicados; e Camarosa e Oso Grande que são muito produtivas e apresentam frutos grandes (Duarte Filho et al., 2007).

Os canteiros foram cobertos com filme de polietileno preto (mulching), com espessura de $30 \mu \mathrm{m}$. Empregou-se a irrigação por gotejamento, utilizando-se tubos gotejadores de polietileno flexível espaçados de $0,30 \mathrm{~m}$.

A estrutura do ambiente protegido foi constituída de arcos de policloreto de vinila (PVC) cobertos com filme de polietileno transparente de baixa densidade (PEBD), com espessura de $150 \mu \mathrm{m}$. $\mathrm{O}$ túnel alto apresentava as seguintes dimensões: 7,0 m de largura, 30,0 m de comprimento e altura máxima de $3,5 \mathrm{~m}$; e o túnel baixo, na largura do canteiro, com comprimento de $24,0 \mathrm{~m}$ e altura máxima de $0,80 \mathrm{~m}$. $\mathrm{O}$ experimento em campo aberto foi implantado utilizando sobre os canteiros apenas mulching de coloração preta.

O manejo dos túneis alto e baixo se constituiu basicamente da abertura e fechamento das laterais, assim, no período de inverno, com ventos fracos e sem chuva, as cortinas eram abertas às $9 \mathrm{~h}$ e fechadas em torno das $16 \mathrm{~h}$. Em períodos de temperaturas mais amenas, com alta pluviosidade e ventos intensos, as cortinas laterais permaneciam abaixadas por todo o período. No caso do túnel alto, as laterais eram abertas em, aproximadamente, $50 \mathrm{~cm}$ em relação ao nível do solo, enquanto que, o túnel baixo, devido à característica do próprio sistema, possibilitava a elevação das laterais em aproximadamente $70 \mathrm{~cm}$.

As mudas foram obtidas a partir de matrizes micro propagadas in vitro e multiplicadas em viveiro, no Setor de Olericultura da Universidade. As mudas utilizadas no plantio foram selecionadas de plantas com diâmetro de coroa superior a $8 \mathrm{~mm}$, consideradas de ótimo padrão, conforme determinado por Ronque (1998).

O controle das plantas daninhas e a remoção de estolões foram feitos manualmente. A irrigação das plantas foi realizada diariamente, durante 15 minutos. O tratamento fitossanitário foi realizado com pulverizações quinzenais de acephate e abamectin para o controle de pulgões e ácaros, respectivamente. O controle de doenças fúngicas foi realizado aplicando-se de forma alternada iprodione e tebuconazole a cada 15 dias.

$\mathrm{Na}$ adubação de plantio foram aplicados $600 \mathrm{~g} \mathrm{~m}^{-2}$ do formulado NPK 04-14-08 e $5 \mathrm{~kg} \mathrm{~m}^{-2}$ de esterco de curral curtido. Nas adubações de cobertura foram utilizadas $30 \mathrm{~g}$ do formulado (NPK) 20-00-20 por parcela a cada 25 dias, iniciando-se 30 dias após o transplante, de acordo com as recomendações para a cultura na região Centro-Sul do Paraná (Ronque, 1998). A partir do florescimento, a cada 20 dias foram aplicados via foliar ácido bórico e sulfato de zinco na concentração de $1 \%$ e $2 \%$, respectivamente. Durante o período de frutificação foram realizadas pulverizações semanais com cloreto de cálcio a $0,4 \%$.

Foram avaliados os efeitos dos três sistemas de cultivo das quatro cultivares de morango sobre a massa média de frutos, a produtividade e o teor de sólidos solúveis. Para tanto, foram amostrados oito frutos maduros por parcela, tomados ao acaso e padronizados quanto ao estádio de maturação, no mês de novembro de 2006 (período correspondente ao pico de produção da cultura na região). O teor de sólidos solúveis, expresso em graus Brix ( ${ }^{\circ}$ Brix), foi determinado por leitura direta em refratômetro de bancada, marca Optech modelo RMT, conforme normas analíticas do Instituto Adolfo Lutz (Instituto Adolfo Lutz, 1985).

Os dados foram submetidos à análise de variância e as médias foram comparadas pelo teste Scott-Knott, a $5 \%$ de probabilidade. Foi realizada a análise conjunta dos experimentos, considerando os três ambientes de cultivo, conforme Gomes (1987).

\section{RESULTADOS E DISCUSSÃO}

A massa média de frutos das cultivares Camarosa, Oso Grande e Sweet Charlie foi maior no sistema de cultivo em túnel alto, diferindo significativamente em relação aos sistemas de cultivo túnel baixo e campo, que por sua vez, não apresentaram diferença entre si. Contudo, esse aumento de massa média não se traduziu em incremento da produtividade em relação ao túnel baixo (Tabela 1), fato este explicado pelo manejo empregado na abertura da lateral do túnel alto, que, possivelmente, devido à menor aeração e ventilação, reduziu a polinização do morangueiro, porém os que se desenvolveram, presumivelmente, drenaram maiores quantidades de fotoassimilados, resultando em frutos com maior massa média. Este fato é corroborado por diversos trabalhos sobre polinização do morangueiro em ambiente protegido (Godoy, 1998; Malagodi-Braga \& Kleinert, 2000; Nogueira-Couto, 2000), onde os autores registram que o morangueiro nesse tipo de ambiente sofre prejuízos na polinização devido à ausência de agentes polinizadores, principalmente artrópodes, resultando em menor número de flores visitadas e polinizadas, imperfeita fertilização do óvulo, apresentando deformações nos frutos e redução de produtividade. Outro aspecto que deve ser considerado é que, 
Tabela 1. Massa média, produtividade média e teor de sólidos solúveis de frutos de quatro cultivares de morango em três ambientes de cultivo (mean fruit mass, yield and levels of soluble solids in fruits of four strawberry cultivars in three cultivation environments). Guarapuava, UNICENTRO, 2007.

\begin{tabular}{llcrcc}
\hline \multirow{2}{*}{ Fatores avaliados } & \multirow{2}{*}{ Ambientes de cultivo } & \multicolumn{4}{c}{ Cultivares } \\
\cline { 2 - 5 } & & Dover & Sweet Charlie & Camarosa & Oso Grande \\
\hline \multirow{2}{*}{ Massa média de frutos $(\mathrm{g})$} & Túnel alto & $9,84 \mathrm{aC} *$ & $12,57 \mathrm{aB}$ & $16,53 \mathrm{aA}$ & $16,09 \mathrm{aA}$ \\
& Túnel baixo & $9,77 \mathrm{aC}$ & $9,80 \mathrm{bC}$ & $14,20 \mathrm{bA}$ & $12,48 \mathrm{bB}$ \\
& Campo & $9,09 \mathrm{aB}$ & $8,45 \mathrm{bB}$ & $12,79 \mathrm{bA}$ & $12,19 \mathrm{bA}$ \\
\hline \multirow{3}{*}{ Produtividade média $\left(\mathrm{t} \mathrm{ha}^{-1}\right)$} & Túnel alto & $44,14 \mathrm{aB}$ & $52,22 \mathrm{aA}$ & $56,74 \mathrm{aA}$ & $54,94 \mathrm{aA}$ \\
& Túnel baixo & $36,98 \mathrm{bC}$ & $45,70 \mathrm{aB}$ & $56,62 \mathrm{aA}$ & $53,16 \mathrm{aA}$ \\
& Campo & $32,85 \mathrm{bB}$ & $32,67 \mathrm{bB}$ & $28,46 \mathrm{bB}$ & $43,01 \mathrm{bA}$ \\
\hline \multirow{2}{*}{ Valores médios de sólidos } & Túnel Alto & $6,45 \mathrm{aB}$ & $7,80 \mathrm{aA}$ & $6,75 \mathrm{aB}$ & $6,90 \mathrm{aB}$ \\
solúveis $\left({ }^{\circ}\right.$ Brix) & Túnel Baixo & $5,93 \mathrm{aA}$ & $7,13 \mathrm{aA}$ & $6,27 \mathrm{aA}$ & $5,70 \mathrm{bA}$ \\
& Campo & $5,87 \mathrm{aB}$ & $7,43 \mathrm{aA}$ & $4,43 \mathrm{bC}$ & $4,80 \mathrm{bC}$ \\
\hline
\end{tabular}

Médias seguidas pelas mesmas letras minúsculas nas colunas e maiúsculas nas linhas não diferem entre si pelo teste de Scott-Knott ( $\mathrm{p}=0,05$ ) (means followed by the same small letter in the columns and capital letter in the rows did not differ from each other through the, ScottKnott's teste, $\mathrm{p}=0,05)$.

no cultivo do morango em ambiente protegido, em função da manutenção das temperaturas mais elevadas por maiores períodos, ocorre maior desenvolvimento vegetativo. Quando o cultivo é feito em espaços mais adensados, pode resultar em redução na produção de frutos, haja vista a competição por fotoassimilados, principalmente pelas folhas sombreadas, que apresentam baixa fotossíntese líquida em função da elevada respiração e fotorrespiração que ocorre neste tipo de ambiente (Taiz \& Zeiger, 2004; Kerbauy, 2004).

A cultivar Dover não sofreu influência do sistema de cultivo quanto à massa média de frutos, entretanto, foi a única cultivar que apresentou, no sistema de cultivo em túnel alto, produtividade superior ao túnel baixo. Essa superioridade pode ser devido, em parte, à menor dependência de agentes polinizadores em ambiente protegido (Antunes et al., 2007), não sendo possível observar, nesse caso, o efeito negativo da falta de polinizadores que ocorre no túnel alto, como foi constatado nas demais cultivares. A cultivar Dover é caracterizada morfologicamente por apresentar arquitetura de dossel ereta e compacta (Shaw, 2004), permitindo, portanto, uma melhor resposta fisiológica sob alta densidade e temperatura. Considerando a média das quatro cultivares em cada ambiente, o cultivo em túnel alto proporcionou a maior massa média de frutos, com 13,71 $\mathrm{g}$ fruto $^{-1}$.

A superioridade do túnel alto em relação ao túnel baixo, sobre a massa média de frutos, pode estar relacionada às variações de temperatura no interior dos dois ambientes e também pelo menor número de frutos produzidos, haja vista a menor circulação de polinizadores no túnel baixo. De acordo com Frisina \& Escobedo (1999), ocorre um gradiente de temperatura no interior do túnel alto, variando, durante o dia, de um mínimo, próximo ao solo, até um máximo, contíguo ao teto. Desta forma, o túnel alto apresenta maior relação volume/área e, assim, maior volume de ar a ser aquecido, tanto a elevação como a redução da temperatura deste ambiente ocorre de forma gradativa. Essas condições, possivelmente, beneficiaram o morangueiro, com temperaturas moderadas no período diurno e pequena elevação das temperaturas mínimas noturnas (Buriol et al., 1993).

Comparando as diferentes cultivares entre si, em cada ambiente de cultivo, foi possível observar que as cultivares Camarosa e Oso Grande apresentaram, via de regra, massa média de frutos superior às cultivares Dover e Sweet Charlie (Tabela 1), confirmando as descrições literárias em relação a essas cultivares (Duarte Filho et al., 2007). Este fato é confirmado observando-se a resposta de cada cultivar nos três ambientes de cultivo conjuntamente (Tabela 2), onde as duas apresentaram a maior massa média de frutos não diferindo entre si significativamente.

Tabela 2. Desempenho médio das quatro cultivares de morango e influência dos ambientes de cultivo na produtividade, massa média e teor de sólidos solúveis (mean performance of four strawberry cultivars and influence of cultivation environments in yield, mean fruit mass and soluble solids content). Guarapuava, UNICENTRO, 2007.

\begin{tabular}{|c|c|c|c|c|c|c|c|}
\hline & \multicolumn{4}{|c|}{ Cultivares } & \multicolumn{3}{|c|}{ Ambientes } \\
\hline & Dover & Sweet Charlie & Camarosa & Oso Grande & Túnel alto & Túnel baixo & Campo \\
\hline Massa média (g/fruto) & $9,60 \mathrm{c}$ & $10,50 \mathrm{~b}$ & $14,71 \mathrm{a}$ & $13,84 \mathrm{a}$ & $13,71 \mathrm{a}$ & $11,56 \mathrm{~b}$ & $10,63 \mathrm{c}$ \\
\hline Produtividade $\left(\mathrm{t} \mathrm{ha}^{-1}\right)$ & $38,61 \mathrm{c}$ & $44,40 \mathrm{~b}$ & $48,22 \mathrm{a}$ & $50,81 \mathrm{a}$ & $52,01 \mathrm{a}$ & $48,12 \mathrm{a}$ & $34,25 \mathrm{~b}$ \\
\hline Sólidos solúveis ( $\left.{ }^{0} \mathrm{Brix}\right)$ & $6,12 \mathrm{~b}$ & $7,50 \mathrm{a}$ & $5,91 \mathrm{~b}$ & $5,88 \mathrm{~b}$ & $6,96 \mathrm{a}$ & $6,26 \mathrm{~b}$ & $5,63 \mathrm{c}$ \\
\hline
\end{tabular}

Médias seguidas pelas mesmas letras nas linhas não diferem entre si pelo teste de Scott-Knott $(\mathrm{p}=0,05)$ (means followed by the same letter in the line, did not differ from each other through the Scott-Knott's test, $\mathrm{p}=0,05$ ). 
Quanto à produtividade, o túnel alto não diferiu do túnel baixo, porém, ambas foram significativamente superiores à obtida no campo aberto, com produção de 52,01 t ha-1 e 48,12 $\mathrm{t} \mathrm{ha}^{-1}$, respectivamente (Tabela 2 ). De acordo com Reisser et al. (2004) a tecnologia de cultivo em ambiente protegido aplicada de forma correta, permite, normalmente alcançar elevadas produtividades. Comparando os sistemas de cultivo em túnel, Lisboa (2000) aponta desvantagens do sistema túnel alto, pois o mesmo requer investimento inicial relativamente alto e não tem apresentado aumento de produção que compense tal investimento. No entanto, esse tipo de estrutura permite que nos dias chuvosos atividades de manejo e colheita possam ser realizadas normalmente.

A cultivar Dover apresentou o menor potencial produtivo no sistema de cultivo em túnel alto, mesmo apresentando vantagens quanto à polinização, como discutido anteriormente. Já no cultivo a campo, a cultivar Oso Grande apresentou a maior produtividade, com incremento de produção de 30,93\%, $31,65 \%$ e $51,12 \%$ em relação às cultivares Dover, Sweet Charlie e Camarosa, respectivamente (Tabela 1 ).

A cultivar Sweet Charlie apresentou os maiores teores de sólidos solúveis nos cultivos em túnel alto e campo, sendo que neste último, as cultivares Camarosa e Oso Grande apresentaram os menores teores. No ambiente túnel baixo não foi observada diferença significativa entre as cultivares, embora a cultivar Sweet Charlie tenha apresentado o maior valor absoluto para essa característica. Observou-se que as cultivares Oso Grande e Camarosa sofreram influência do cultivo protegido com elevação dos sólidos solúveis em relação ao cultivo a campo. Entretanto, a cultivar Oso Grande não apresentou diferença significativa no teor de sólidos solúveis nos frutos provenientes dos cultivos em túnel baixo e campo (Tabela 1).

Considerando apenas o ambiente de cultivo, o túnel alto foi o que apresentou a maior influência no aumento dos teores de sólidos solúveis, seguido pelo cultivo em túnel baixo e a campo, todos diferindo significativamente entre si (Tabela 1). Essa superioridade observada nos frutos obtidos em túnel alto se deve, presu- mivelmente, às maiores temperaturas propiciadas pelo sistema, que, conforme descrito por Scott \& Lawrence (1975), influenciam na qualidade do fruto em função da maior síntese de compostos secundários, além de permitir que a planta acumule maiores concentrações de açúcares solúveis. Conforme Morgan (1999), além das condições ambientais, o valor de sólidos solúveis também é afetado por aspectos nutricionais e varietais. Este fato foi observado na cultivar Sweet Charlie, a qual apresentou o maior valor de sólidos solúveis (Tabela 2), confirmando a descrição de Duarte Filho et al. (2007) que consideram esta cultivar de sabor adocicado.

De maneira geral o ambiente protegido proporciona melhores condições ao desenvolvimento e à sanidade das plantas, pois as condições climáticas proporcionadas por esse ambiente permitem maior expressão das atividades fisiológicas, por meio de uma maior fotossíntese líquida e, conseqüentemente maior acúmulo de carboidratos, que resultam no incremento de massa seca e açúcares redutores e não redutores (Taiz \& Zeiger, 2004; Kerbauy, 2004), compostos que em altas concentrações melhoram as características físico-químicas dos frutos (Chitarra \& Chitarra, 2005).

A menor produtividade, massa média e teor de sólidos solúveis observados no cultivo a campo estão, principalmente, relacionados ao molhamento da parte aérea, que além de contribuir para o desenvolvimento de doenças fúngicas e bacterianas, propicia a lavagem do pólen das inflorescências, reduzindo a taxa de fertilidade (Duarte Filho et al., 2007).

Por meio dos resultados obtidos para produtividade e massa média de frutos, constatou-se que a cultivar Camarosa apresentou excelente desempenho, tanto em túnel baixo, quanto em túnel alto. Para cultivo a campo, Oso Grande foi a cultivar que apresentou melhor desempenho. Quanto ao acúmulo de sólidos solúveis, a cultivar de maior destaque foi Sweet Charlie, nos três ambientes de cultivo avaliados.

\section{REFERÊNCIAS}

ANTUNES OT; CALVETE EO; ROCHA HC;
NIENOW AA; CECCHETTI D; RIVA E; MARAN RE. 2007. Produção de cultivares de morangueiro polinizadas pela abelha jataí em ambiente protegido. Horticultura Brasileira 25: 094-099.

BUENO SCS; MAIAAHN; TESSARIOLI NETO J. 2002. Florescimento de 17 cultivares de morangueiro (Fragaria $\mathrm{x}$ ananassa Duch.), em São Bento do Sapucaí-SP. In: CONGRESSO BRASILEIRO DE FRUTICULTURA, 17. Anais... Belém: SBF (CD-ROM).

BURIOL GA; SCHNEIDER FM; ESTEFANEL V; ANDRIOLO JL; MEDEIROS SLP. 1993. Modificações na temperatura mínima do ar causada por estufas de polietileno transparente de baixa densidade. Revista Brasileira de Agrometeorologia 1: 43-49.

CARVALHO SLC; NEVES CSVJ; BÜRKLE R; MARUR CJ. 2005. Épocas de indução floral e soma térmica do período do florescimento à colheita de abacaxi 'Smooth Cayenne'. Revista Brasileira de Fruticultura 27: 430-433.

CHITARRA MIF; CHITARRA AB. 2005. Póscolheita de frutos e hortaliças: fisiologia e manuseio. Lavras: FAEPE. 785p.

CONTI JH; MINAMI K; TAVARES FCA. 2002. Produção e qualidade de frutos de morango em ensaios conduzidos em Atibaia e Piracicaba. Horticultura Brasileira 20: 10-17.

DUARTE FILHO J; ANTUNES LEC; PÁDUA JG. 2007. Morango: conquistando novas fronteiras. Informe Agropecuário 26: 20-23.

EMBRAPA - CENTRO NACIONAL DE PESQUISA DE SOLOS. 2006. Sistema brasileiro de classificação de solos. Rio de Janeiro: Embrapa. 306p.

FRISINA VA; ESCOBEDO JF. 1999. Balanço de radiação e energia da cultura de alface em estufa de polietileno. Pesquisa Agropecuária Brasileira 34: 1775-1786.

GODOY WI. 1998. Polinização entomófila em duas cultivares de morangueiro (Fragaria $X$ ananassa Duch.) sob diferentes coberturas do solo. Porto Alegre: UFRGS. 162p (Tese mestrado)

GOMES FP. 1987. Estatística experimental. 12 ed. Piracicaba: ESALQ. 467p.

GOTO R; TIVELLI SB. 1998. Produção de hortaliças em ambiente protegido: condições subtropicais. São Paulo: Fundações Editoras da UNESP. 319p.

GROPPO GA; TESSARIOLINETO J; BLANCO MCSG. 1997. A cultura do morangueiro. 2 ed. Campinas: CATI. 27p. (Boletim Técnico, 201).

INSTITUTO ADOLFO LUTZ. 1985. Normas analiticas do Instituto Adolfo Lutz: métodos químicos e físicos para análises de alimentos. 3 ed. São Paulo: IAL. 371p.

JONES HG. 1992. Plants and microclimate. 2 ed. Cambridge: University Press. 428 p.

KERBAUY GB. 2004. Fisiologia vegetal. Rio de Janeiro: Guanabara Koogan. 452p.

LISBOA JMM. 2000. O sistema de cultivo do morango no município de Feliz - RS. Porto Alegre: UFRGS. 297p. (Tese mestrado).

MALAGODI-BRAGA KS; KLEINERT AMP. 2000. Os meliponíneos e a polinização do morangueiro em estufas. In: CONGRESSO 
BRASILEIRO DE APICULTURA, 14. Resumos... Florianópolis: CBA (CD-ROM).

MORGAN L. 1999. Fruit flavour and hydroponics. In: MORGAN L (ed). The best of practical hydroponics and greenhouses. Austrália: Casper Publications. p. 152-157.

NOGUEIRA-COUTO RH. 2000. Comportamento forrageiro de abelhas e sua importância na polinização de plantas domesticadas. In: CONGRESSO BRASILEIRO DE APICULTURA, 14. Resumos... Florianópolis: CBA (CD-ROM).

PIRES RCM; PASSOS FA;TANAKA MAS. 1999. Irrigação do morangueiro. Informe Agropecuário 20: 52-58.

REISSER JÚNIOR C; ANTUNES LEC; RADIN B. 2004. Técnicas de proteção da cultura do morangueiro com filmes de polietileno de baixa densidade. In: SIMPÓSIO NACIONAL DO MORANGO. Pelotas: Embrapa Clima Temperado. 296p. (Documentos, 124).

RONQUE ERV. 1998. Cultura do morangueiro: revisão e prática. Curitiba: EMATER-PR. 206p.

SCATOLINI ME. 1996. Estimativa da evapotranspiração da cultura de crisântemo em estufa a partir de elementos meteorológicos. Piracicaba: USP-ESALQ. 70p. (Tese mestrado).

SCOTT DH; LAWRENCE FJ. 1975. Strawberries. In: JANICK J; MOORE NM (eds). Advances in fruit breeding. Indiana: Purdue University Press. p.71-92.

SHAW DV. 2004. Strawberry production systems, breeding and cultivars in Califórnia. In: SIMPÓSIO NACIONAL DE MORANGO. I Encontro de pequenas frutas e frutas nativas do mercosul. Pelotas: Embrapa Clima Temperado. p. 16-21. (Documentos, 124).

TAIZ L; ZEIGER E. 2004. Fisiologia vegetal. Porto Alegre: Artmed. 719p.

VÁSQUEZ MAN; FOLEGATTI MV; SILVA DIAS N; SILVACR. 2005. Efeito do ambiente protegido cultivado com melão sobre os elementos meteorológicos e sua relação com as condições externas. Engenharia Agrícola 25: 137-143.

VERDIAL MF. 2004. Frigoconservação e vernalização de mudas de morangueiro (Fragaria $\mathrm{x}$ ananassa duch.) produzidas em sistemas de vasos suspensos. Piracicaba: USPESALQ. 71p. (Tese doutorado). 